\title{
Simplex-centroid mixture formulation for optimised composting of kitchen waste.
}

\begin{abstract}
Composting is a good recycling method to fully utilise all the organic wastes present in kitchen waste due to its high nutritious matter within the waste. In this present study, the optimised mixture proportions of kitchen waste containing vegetable scraps (V), fish processing waste $(\mathrm{F})$ and newspaper $(\mathrm{N})$ or onion peels $(\mathrm{O})$ were determined by applying the simplex-centroid mixture design method to achieve the desired initial moisture content and carbon-to-nitrogen $(\mathrm{CN})$ ratio for effective composting process. The best mixture was at $48.5 \% \mathrm{~V}, 17.7 \% \mathrm{~F}$ and $33.7 \% \mathrm{~N}$ for blends with newspaper while for blends with onion peels, the mixture proportion was $44.0 \% \mathrm{~V}, 19.7 \% \mathrm{~F}$ and $36.2 \% \mathrm{O}$. The predicted responses from these mixture proportions fall in the acceptable limits of moisture content of $50 \%$ to $65 \%$ and $\mathrm{CN}$ ratio of $20-40$ and were also validated experimentally.
\end{abstract}

Keyword: Kitchen waste; Composting. 